\title{
Walden dos: \\ crítica al paradigma económico moderno
}

\author{
Liliana Olarte Rodríguez* \\ Universidad de LosAndes
}

Recibido: Mayo 25 de 2005

Revisado: Mayo 31 de 2005

Aceptado: J unio 8 de 2005

\section{Resumen}

Luego de publicarse, Walden Dos sería rechazado a causa de falsas concepciones que sugerían que la obra era la defensa y representación de los valores sociales y económicos capitalistas. Sin embargo, un análisis detallado muestra cómo la edificación de la sociedad propuesta por Skinner critica los pilares fundamentales del paradigma económico y social actual, como lo son el egoísmo como base para el bienestar social, el consumismo como motor económico y la "libertad" según el capitalismo. Si bien Walden Dos no deja de ser una utopía, deja entrever que es necesario implementar los principios de la ingeniería de conducta, aspecto poco considerado por disciplinas como la economía, la ciencia política, entre otras, si se quieren resolver las falencias del sistema actual.

Palabras clave: análisis del comportamiento, psicología cultural, economía, Walden Dos, ingeniería de la conducta.

\section{Abstract}

After being published Walden Two was rejected due to false conceptions that suggested that the novel 
was the defense and representation of the economic and social values of capitalism. However a more detailed analysis shows how the construction of the society proposed by Skinner critiques the fundamental pillars of the current economic and social paradigms such as egotism as the base for social welfare, the growing acquisition of material goods as the motor of the economy and "freedom" according to the capitalistic dogmas. Although Walden Two is a utopia, it reveals how is necessary to introduce the principles of the behavior engineering, aspect that has not been widely considered by fields like Economics and Politics, if we want to solve the problems that the current social structure suffers.

Key words: behavior analysis, cultural psychology, economic, Walden Two, behavior engineering.

Durante los últimos tres siglos, el paradigma reinante en economía ha sido abordado bajo las hipótesis del egoísmo y el enriquecimiento desmedido, y ha tenido como sustento organizador de cualquier grupo social o político la tan alabada doctrina del laissez-faire. Con base en estos principios, se ha convencido no sólo a los estudiosos del tema, sino a la sociedad en general de que éste es el abordaje correcto por diversas razones que lo justifican: la alta complejidad de los modelos que explican y sostienen dicho paradigma, y las supuestas cientificidad y experimentabilidad de sus preceptos.

Sin embargo, en años recientes hemos sido testigos de cómo esta visión dista cada día más de satisfacer no sólo una necesidad explicativa que proporcione coherencia interna al estudio de la economía, sino que además no ha sido efectiva al momento de arrojar luz sobre los problemas más apremiantes que atacan a los individuos y a las comunidades económicas.

Contrario a lo que se pensaría, se ha creído que el error del sistema ha radicado precisamente en la utilización incorrecta de sus principios y en una imposibilidad de su aplicación efectiva, con lo cual se ha llegado a concluir que sólo un rigor extremo en dicha aplicación sumado a una fe acérrima en sus dogmas podrá lograr resolver los problemas más apremiantes. Pero paradójicamente los países más pobres, que son por lo general los más frecuentemente instados a seguir dichas normas, se desviven entre la pobreza, la miseria y el sometimiento, mientras que otras naciones del mundo experimentan un enriquecimiento continuo y creciente.

Pareciera, pues, que el panorama económico no pudiera escapar del círculo vicioso evidente en todo el sistema, esto es, parara poder mejorar en términos de bienestar es necesario reducir las posibilidades del otro. Este principio fundamentalista parece en apariencia ir en contra del sistema neoclásico reinante, según el cual un entendimiento óptimo de los recursos que se poseen, así como una adecuada implantación de políticas, tales como la división del trabajo y el libre comercio, entre otras, lograrán un óptimo social en el cual todos salgan beneficiados. Sin embargo, el testimonio vivo parece ir en contra de la teoría y, aun peor, tal parece que el número de beneficiados es cada vez menor, pero cada vez más poderoso, mientras que la porción restante que posibilita y sustenta el enriquecimiento de dichos favorecidos es cada vez mayor.

A causa de lo anterior, si bien los intentos por explicar el problema, así como sus posibles soluciones, han logrado hallar de cierta manera el epicentro del mismo, han distado de arrojar luz sobre la solución y sí, en cambio, se han prestado para tergiversaciones y confusiones sobre la verdadera estructura de éste. Milton Friedman 
(1966), uno de los economistas neoclásicos más importantes, por ejemplo, ha visto cómo todo problema económico no es un fenómeno aislado, sino una estructura sostenida por un marco social intrínsicamente ligado con los individuos.

De forma similar a la posición de B.F Skinner (1976) en Walden Dos, Friedman considera al gobierno central como una amenaza a la libertad, pues ve la posible concentración de poder en sus manos como un peligro inminente. Sin embargo, y paradójicamente, considera al gobierno como único garante de la conservación de dicha libertad, con lo cual no logra establecer una clara línea divisoria entre el papel del Estado y el mercado. Por esta razón, la defensa de los neoclásicos de un mercado autorregulado, que es autosuficiente, es inestable, pues como se puede vislumbrar en su argumento, le resulta imposible a este autor, como a muchos otros neoclásicos, separar la esfera económica de la acción política y ésta, a su vez, de la esfera social.

B.F Skinner (1948), por el contrario, defendió esta visión anti-concentración del poder en el gobierno, pero fue coherente con el desarrollo de las razones en defensa de dicha posición. Así pues, si bien defiende que la política y la concentración del poder, en unas falsas ilusiones democráticas no dejan de ser algo ilógico, no considera que deba existir un estamento político superior a todo, que pueda efectivamente, bajo diferentes métodos (persuasivos, legislativos o violentos), garantizar tales derechos de libertad. Por el contrario, considera que todo sistema económico debe estar sostenido por unas bases sociales y unos principios individuales dados, razón por la cual para lograr una coherencia entre los fines económicos perseguidos y el beneficio multitudinario deben renovarse los principios estructurales de dicha sociedad y debe hacerse una revisión completa de los principios y los móviles que dirigen dicho grupo humano.

En Walden Dos, Skinner (1948) desvirtúa muchos de estos principios estructurales de una sociedad que, según los neoclásicos, no sólo son principios básicos y necesarios para el funcionamiento del sistema, sino principios inherentes a los miembros del mismo. Entre estos pilares del sistema librecambista se encuentra uno que aboga por un principio de no-saciedad (ver figura.1), principio según el cual todo individuo guiado por móviles egoístas desea el consumo desmedido como única medida efectiva de satisfacer sus necesidades y sus deseos más básicos.

Sin embargo, y como lo ha puesto de relieve Skinner (1948) en el desarrollo de la utopía de la comunidad Walden, estos sustentos, lejos de ser una realidad factible, son conductas individuales que han sido condicionadas, aprendidas y constantemente reforzadas, lo que en cualquier caso desvirtúa el fundamento que defiende su innaticidad respecto a la naturaleza individual.

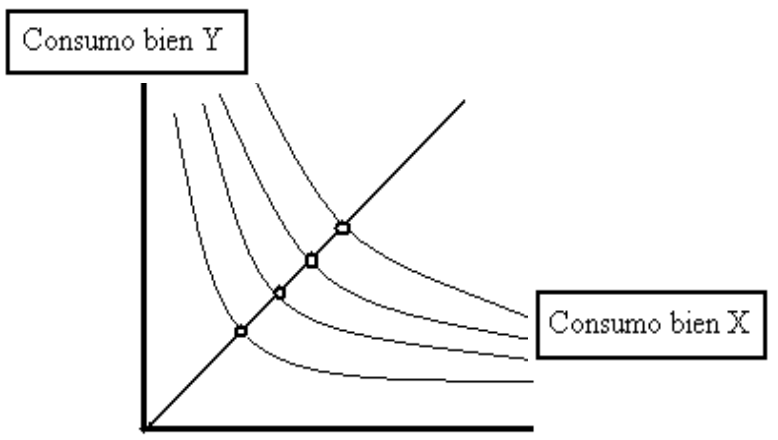

Figura 1. Representación de Curvas de Indiferencia. Las líneas curvas representan las diferentes cestas de consumo que son accesibles para el consumidor (curvas de indiferencia) dados unos diversos niveles de ingreso descritos por las intersecciones con la línea diagonal. Según la teoría neoclásica, entre más dinero tenga el consumidor, deseará llegar a una curva de indiferencia más alta; es decir, a un nivel de consumo superior. Éste siempre es su obj etivo.

Así pues, en esta comunidad Walden no están a merced de modistos comerciales, pues al contrario de nuestra sociedad actual fueron capaces de entender la realidad de los principios comerciales: entendieron que pasar de moda no era un proceso natural, sino un cambio premeditado que destruye la belleza del vestido del año anterior y lo deja sin valor, contrario a la propuesta de la sociedad de consumo en la que vivimos y en la cual esta 
ansia infinita de adquisiciones es patrocinada por el entendimiento del consumo como el verdadero motor de la economía y generador de riqueza, lo cual crea así un círculo vicioso.

Para lograr el acometido anterior, los habitantes de la comunidad Walden Dos debieron modificar sus alicientes cambiando sus gustos; al fomentar la variedad lograron efectivamente evitar el gasto superfluo que supone andar cambiando de estilos frecuentemente, pues ese cambio casi diario de etiquetas en el mundo actual provoca una demandada desmedida no sólo de ropa, sino de objetos varios que aún tienen una vida útil explotable (Skinner, 1948).

En esta lucha contra los cánones comerciales, la comunidad Walden llevó a cabo pruebas experimentales que demostraron el papel central de la publicidad en la creación de estas falsas ilusiones de vida. Los titulares llamativos, las luces deslumbrantes y demás lo único que buscan es envenenar el público inerte; por el contrario, en esta comunidad se busca despertar el interés y el entusiasmo en un tema dado a causa de los efectos o consecuencias que éste le haya permitido vivir al individuo, entendiendo que la emoción no es más que un reflejo sujeto de ser condicionado (Skinner, 1948).

Esta situación ha dejado entrever cómo lejos de ser estos principios estructurales referentes innatos del sistema individual, constituyen dogmas que han sido creados para que coincidan con los ánimos capitalistas de acumulación estrepitosa de capital, de tal manera que las modas son una invención, una creación que ha logrado eficazmente modificar la conducta humana en pro del enriquecimiento de unos pocos productores, cambiando las consecuencias normales que traía la entrada en desuso de ciertos bienes por el placer de encajar dentro de cierto estatus social 0 de ser capaces de identificarse con cierto estereotipo dominante.

Para lograr una lucha efectiva en contra del consumismo desmedido, en la comunidad Walden no se permiten los extremos en ninguna de las dos direcciones: ni el traje de gala ni las vestimentas raídas son vistas como normales en una sociedad que pretende mostrar verídicamente cómo es el proceso de utilización y desuso de los bienes materiales. De esta manera, el traje de gala constituye una forma de ostentoso consumo que causa una percepción de los demás como seres distantes y diferentes del resto; por su parte, los trajes raídos constituyen un indicio de pobreza, una protesta contra todo un sistema de vida. Se constituyen así los trajes elegantes en señales de riqueza para conseguir riqueza y los trajes raídos como instrumentos de pobreza para conseguir pobreza (Skinner, 1948).

De igual forma, en la comunidad Walden se encontró que otro de los principios que rige el consumo desmedido es la integración de falsos principios a las características de las posesiones. Así pues, la utilización práctica debe primar sobre el interés superfluo, o de lo contrario se caerá en la trampa de la sociedad actual. En la utilización de las bandejas comestibles, por ejemplo, lejos de considerar su utilización como centrada en objetivos decorativos o estéticos se ve su utilidad funcional, razón por la cual no tienen un motivo decorativo específico o un color dado; son transparentes para facilitar su lavado y uso, pues entienden que el aseo es una actividad concerniente a toda la sociedad y no a una porción marginada de la misma contratada con salarios miserables como sucede en nuestra sociedad actual por efecto de la aplicación de creencias centradas en objetivos según los cuales los fines estéticos priman sobre los fines prácticos.

Los argumentos anteriores muestran que este principio de la innaticidad de satisfacción de móviles consumistas puede ser desvirtuado. Además, Skinnner en su análisis de las sociedades modernas prueba cómo la propensión natural al intercambio, otro de los principios neoclásicos más fuertes, es también una falacia, un invento capitalista que ha sido incapaz de ver dentro de las estructuras sociales para descifrar lo que es verdaderamente conveniente para las mismas. 
Según este principio neoclásico, el intercambio es un proceso "natural" al hombre en tanto poseedor de propensiones innatas a la satisfacción de sus necesidades y deseos, y esa naturaleza en pro del enriquecimiento encuentra en el intercambio el único medio efectivo para conseguir los fines buscados.

Según Smith (1776), considerado el fundador de la disciplina neoclásica, la división del trabajo, que supuestamente tantas ventajas reporta, no tiene su origen en la sabiduría humana, sino es la consecuencia gradual y necesaria de una cierta propensión de la naturaleza humana que aspira a una cierta utilidad: la propensión a permutar, cambiar y negociar una cosa por otra. En ese sentido, en una sociedad civilizada, según lo explica Smith, el hombre necesita a cada instante la cooperación y asistencia de la multitud, en tanto que su vida entera apenas le basta para conquistar la amistad de contadas personas. Sin embargo, el hombre reclama en la mayor parte de las circunstancias la ayuda de sus semejantes y en vano puede esperarla sólo por benevolencia, así pues la conseguirá con mayor seguridad interesando en su favor el egoísmo de los otros, haciéndoles ver que es ventajoso para ellos hacer lo que les pide; de esta manera no invoca sus sentimientos humanitarios, sino su egoísmo.

Es posible concluir, entonces, que para los neoclásicos es la suma del egoísmo individual 0 , en términos de la microeconomía moderna, la maximización del beneficio individual, el que conduciría por una vía un poco ilógica e incoherente al bienestar general. Skinner, en su exposición de la comunidad Walden, desmiente que sea el egoísmo el que verdaderamente conduzca al bienestar general de la sociedad, así como también que los orígenes del intercambio, guiados por este egoísmo, sean verdaderamente naturales al individuo y sí, por el contrario, otra de las invenciones de la sociedad capitalista.

La comunidad Walden es el testimonio de una de las verdades que han tratado de ser ocultadas tras los infundados principios capitalistas: la suma de todos los egoísmos individuales o la maximización del beneficio individual difícilmente nos llevará al bienestar social en el cual todos tendremos un nivel de beneficio similar. Por supuesto, Skinner no ha sido el único en ver esta realidad muchas veces ignorada por los economistas y diversos analistas. J ohn Nash, ganador del premio Nobel de Economía, propuso una teoría un poco nefasta sobre el resultado de las relaciones egoístas en comunidad.

Según Nicholson (2002), en su explicación del modelo de Nash, todas las relaciones individuales pueden definirse como juegos. Cada interacción, cada problema a abordar es un juego en el cual existen diversos jugadores con diferentes estrategias. De acuerdo con esta teoría, al existir un número elevado de individuos en una sociedad es difícil que los jugadores conozcan de antemano la estrategia que el otro jugador empleará, y más difícil aún es que los jugadores se conozcan entre sí, con lo cual cualquier estrategia subjetiva o condescendiente queda inicialmente descartada.

Al resultado del juego se llega porque cada individuo piensa primero en sí mismo que en el beneficio común; simultáneamente, el resto de jugadores piensa de la misma manera. A causa de lo anterior el juego tiene un resultado no cooperativo en el cual todos obtienen una ganancia 0 un beneficio inferior al que podrían obtener si tuvieran una estrategia más condescendiente, es decir, una estrategia de tipo cooperativo (ver tabla 1 y tabla 2 ). Sin embargo, es un hecho que tales valores cooperativos son difíciles de hallar en una sociedad como la actual; por lo cual es difícil que el resultado del juego sea diferente, y sólo una modificación conductual dentro de las micro y macro estructuras sociales sería capaz de hacer que los individuos prefirieran la estrategia de cooperación sobre la no cooperativa.

Otro análisis en este mismo sentido es el de Matt Ridley en su libro Los orígenes de la virtud. En él, hace un estudio de las estrategias utilizadas en un sinnúmero de juegos; las conclusiones de 
Tabla 1. Representación matricial del Equilibrio de Nash

\begin{tabular}{l|c|c|c|}
\hline \multirow{2}{*}{} & \multicolumn{2}{|c|}{ JUGADOR B } \\
\cline { 3 - 4 } & Estrategia no & 5,5 & Estrategia cooperativa \\
\hline \multirow{3}{*}{ J UGADOR A } & cooperativa & & 11,2 \\
\cline { 3 - 4 } & Estrategia cooperativa & & 10,10 \\
\hline
\end{tabular}

Tabla 2. Significado de la representación matricial

\begin{tabular}{|c|l|}
\hline Resultado & \multicolumn{1}{|c|}{ Significado } \\
\hline 5,5 & Beneficio obtenido fruto de un juego no cooperativo (Equlibrio de Nash) \\
\hline 2,11 & Resultado obtenido cuando el jugador A elige cooperar y el jugador B decide no \\
& cooperar \\
\hline 11,2 & Resultado obtenido cuando el jugador A elige no cooperar y el jugador B elige \\
\hline 10,10 & Resultado obtenido cuando los dos jugadores eligen una estrategia cooperativa \\
\hline
\end{tabular}

dicho estudio muestran una alta aplicabilidad en las sociedades. En su análisis, Ridley opera con juegos que se llevan a cabo no a nivel real, sino a nivel electrónico, es decir, hace uso de computadoras y otros elementos tecnológicos que compiten entre sí en un juego repetido que implica el uso de diversas estrategias. Algunos individuos virtuales tienen estrategias benévolas y otros retaliadoras.

En un principio, los resultados del experimento arrojaron que las estrategias menos benévolas eran las ganadoras, lo cual ratificó una vez más que el egoísmo y la falta de condescendencia en las sociedades no es algo premeditado, sino algo necesario para la supervivencia en sociedad. Sin embargo, después de una aplicación de juegos repetidos, se encontró que los estrategas que perdonaban algunas retaliaciones resultaban ser los vencedores, mientras que los demás eran eliminados, con lo cual es posible concluir que las estrategias egoístas si bien en un principio sirven como frente de defensa, a largo plazo no son un buen sustento del entramado social justo. Con lo anterior es posible vislumbrar cómo para construir una sociedad más igualitaria y justa no es viable continuar con una visión darwiniana de las relaciones humanas en la cual por selección natural deba primar el egoísmo y la falta de altruismo, pues esta línea de pensamiento conlleva un ciclo de destrucción social.

En contraposición a estas doctrinas egoístas, la comunidad Walden se fundamenta en principios basados en experimentos conductuales, experimentos que mostraron que una sociedad utópica y perfecta no podía descansar bajo móviles personalistas, pues éstos causaban el be- 
neficio de unos por el detrimento de otros. Las consecuencias de conductas individualistas quedan develadas en Walden Dos cuando logra ver el motor que verdaderamente hace que en las sociedades se genere una propensión al intercambio: la competencia por la mayor acumulación de bienes y capital, el enriquecimiento.

Por lo anterior, en la comunidad Walden no existe el dinero ni sustitutos cercanos del mismo; existe un límite de cuatro créditos de trabajo que deben cumplirse diariamente y un acumulado anual mínimo que debe cumplirse. Todos los productos y servicios son gratis, se pagan con los mil doscientos créditos al año que cada persona consigue fruto de su esfuerzo personal. Este análisis pone de relieve una vez más que es necesario romper con el ciclo darwiniano dentro de las macroestructuras sociales, o de lo contrario es imposible construir una sociedad en donde el bienestar esté distribuido entre sus miembros de manera equitativa.

Para evitar la elección de unos trabajos sobre otros, lo cual favorece la acumulación desmedida de riqueza, el valor de los créditos se otorga de acuerdo con las necesidades de la comunidad, pues se constató que un sistema basado en las ganancias es malo, incluso cuando el obrero consigue para sí los beneficios, porque el esfuerzo del trabajo suplementario no es posible de ser compensado con ningún beneficio por grande que sea. De tal manera que se asignan diferentes cantidades de créditos a las diversas clases de trabajo y se las ajusta de vez en cuando con la demanda, con lo cual los trabajos desagradables tienen más valor y, si algún tipo de trabajo parece que se rehuye sin causa, se fuerza una preferencia mediante su valor.

De igual manera, se estimula para que no existan móviles que conduzcan a la sobrepoblación en una de las muchas profesiones existentes, así pues se educa a los jóvenes para tengan unos gustos variados, para que sean conscientes de la utilidad de una profesión dada, para que no se opongan al sistema según el cual hay un número limitado de plazas para ejercer una profe- sión dada y evitar así fines lucrativos que vayan en contra de los intereses comunes. Vale la pena anotar que también es imperante en la comunidad, para evitar la primacía de estos móviles económicos, que todos los individuos conozcan las diversas ocupaciones, ejecuten oficios varios. Como resultado de lo anterior, se logran no sólo mejores trabajadores, sino mejores administradores que conocen y comprenden a fondo las necesidades del administrado.

Con un sistema como el implementado en la comunidad Walden no sólo se logra la evitación de la primacía del egoísmo individual, sino una mayor productividad. Así pues, en Walden Dos no existe la clase ociosa ni los ancianos prematuros, imposibilitados, tampoco criminales ni enfermos. No existe el paro obrero debido a la mala planificación y tampoco existe gente que acumule capital sin hacer trabaj o. La razón para lo anterior es que al escoger una ocupación dada, con un tiempo bastante reducido comparado con los estándares laborales actuales y, además, sin un jefe o ente superior en el cual deba depositar todo su rendimiento laboral, es difícil que saquen el máximo partido a las máquinas y a los métodos automatizados utilizados.

Esta elección profesional, así como un amplio rango de tiempo para el ocio, junto con la garantía de la satisfacción de todas las necesidades básicas, hacen del habitante de Walden Dos un individuo que se aleja de los sometimientos que los trabajadores en el sistema capitalista deben enfrentar. En este punto, aquella noción de que la libertad es el primer paso para el libre desarrollo del individuo entra en tela de juicio, pues valdría la pena empezar a cuestionar la validez efectiva de aquella libertad por la que tanto abogan los neoclásicos viendo que los individuos en dicho sistema están sometidos a la voluntad de poderosos capitalistas, y cuando no se encuentran en esta situación se encuentran atrapados por encajar en el status consumista que van imponiendo los cánones sociales.

Para Milton Friedman (1966), el capitalismo competitivo es el sistema de libertad económica y 
condición necesaria para la libertad política, concluyendo así que el libre albedrío individual nos conducirá a una situación en la que la elección será la del egoísmo individual, egoísmo que, a su vez, nos conducirá al bienestar social. Este supuesto indica que cada uno debe preocuparse por acrecentar en gran medida su acervo posible de bienes, así como adquirir el mayor número del mismo para satisfacer sus necesidades. En contraposición con lo expuesto por Friedman (1966), Skinner concibe la libertad económica como el fruto de la combinación de un altísimo nivel de vida con un consumo bajo de bienes.

Según Skinner, se debe aplicar el principio de Thoreau de evitar la propiedad innecesaria, pues si se aboga por un elevado consumo de bienes se caerá en el círculo vicioso de la creación de falsas necesidades, con lo cual jamás se estará satisfecho con la situación presente. De igual forma, este principio garantizará que no se fijen unos estándares de vida inalcanzables, como los que padece la sociedad actual en la cual al obrero promedio le lleva un número casi infinito de años conseguir un "simple techo", pues no existe la presión artificial de incentivos emotivos que estimulan un consumo innecesario. Así, se logra que todo el dinero conseguido pertenezca a la comunidad, de tal manera que no existe una clase privilegiada ni una clase explotada.

Desde otra perspectiva, si se quiere parealela, es importante analizar en el marco del análisis del individuo como ente económico, parte de una comunidad y trabajador, el rol de los sistemas productivos en la vida laboral. Para Skinner, en palabras de Frazier, y al igual que para los neoclásicos, el éxito económico estriba en la implantación de la tecnología en los procesos productivos. A pesar de que podría pensarse que, al ser la comunidad Walden una sociedad autosuficiente, sería entonces primitiva en sus formas productivas, Ia realidad es la contraria. Sin embargo, el enfoque dado a la tecnificación del proceso productivo en la sociedad actual, en las épocas de la revolución industrial y en la comunidad Walden es significativamente divergente. El error de las sociedades capitalistas, en palabras de
Skinner, ha sido pensar que como existía una abundante riqueza en mano de obra, superior a la materia prima y capital, lo mejor era llevar la utilidad de la mano de obra al máximo.

A partir del fenómeno anterior, empezaría a gestarse uno de los fenómenos más nefastos en las comunidades productivas capitalistas del presente: Ia plusvalía. Este término, introducido por el economista Karl Marx (1982), fue el producto de observar que al masificar intensivamente la producción, fruto de la obtención de unas ganancias exponencialmente crecientes, los beneficios terminaban en manos de los propietarios del capital y los medios de producción y no en el responsable del éxito de dicho proceso productivo: el trabajador. Así pues, empieza a gestarse una distancia abismal entre la retribución al trabajo percibida por el trabajador asalariado y la recibida el capitalista. La riqueza empezaría a concentrarse en unas pocas manos empezando a profundizar la brecha ya existente entre las diversas clases.

En la comunidad Walden nunca hay trabajo de sobra, pues éste debe mantenerse en un nivel mínimo por razones psicológicas; de hecho, una de las razones para la creación de Walden fue el desprecio hacia la vida moderna. No hay incentivos para que exista una masiva producción, con consecuencias nefastas para el trabajador, que a su vez conduciría al establecimiento del intercambio frecuente como uno de los pilares económicos de la sociedad. De igual forma, se educa a los ciudadanos desde una edad temprana para que no centren su atención en una profesión dada guiados por móviles de lucro, tampoco existen profesiones en un estatus mayor que otras, Io cual evita cualquier posible surgimiento de móviles egoístas.

En este punto, se hace necesario mencionar nuevamente la reiterada diferencia entre la libertad concebida por el sistema capitalista y la libertad concebida por Skinner en el desarrollo de su utopía: Walden Dos. Para el sistema neoclásico, la libertad estriba en ser capaces de crear un beneficio general, guiados por un egoís- 
mo individual y maximizando los beneficios posibles entre todas las opciones existentes. Sin embargo, esta libertad, como se ha visto expuesto en el desarrollo del tema y como ha sido atestiguado por las civilizaciones modernas, tiene muchas consecuencias nocivas, como por ejemplo el sometimiento de los trabajadores asalariados - la mayoría de la sociedad- a los propietarios del capital y los medios de producción, que constituyen una minoría, o la concentración del proyecto de vida en lograr un ideal consumista irrealizable dadas las crecientes brechas entre las diversas clases sociales.

Al otro lado del esquema, en oposición, se encuentra la visión de libertad propuesta por Skinner. Según su propuesta, la libertad jamás podrá ser alcanzada con el seguimiento del egoísmo individual, pues si se unen todas las fuerzas individuales en pro de este fin, se logrará un resultado perjudicial para todos los miembros de la comunidad, como lo atestiguan Nash y Ridley. En ese orden de ideas, la verdadera libertad es aquella en la que prima el beneficio común al individual, pues es la única que efectivamente hará la vida del individuo en comunidad más beneficiosa y provechosa. De igual forma, no existe libertad si el individuo está sometido a regímenes laborales déspotas donde todo su esfuerzo no es proporcionalmente recompensado por los resultados, y en el que su ideal de vida es alcanzar unos cánones de consumo. Por el contrario, sólo existe libertad si el individuo es realmente libre de disfrutar su vida laboral así como su vida en comunidad, una vida en la cual le estén garantizados sus derechos y necesidades básicas.

En ese sentido, se proponen con cautela las siguientes conclusiones, dadas las dimensiones ideológicas del tema en cuestión. En primera instancia, se puede apreciar que hay un hecho común a todos los argumentos dados: la divergencia entre los supuestos económicos que manejan las diversas escuelas de pensamiento como la neoclásica, ampliamente expuesta aquí, la neokeynesiana y la marxista, y la efectiva realidad que percibimos y atestiguamos verdadera- mente. La razón para lo anterior quizás estribe en una de las crudas afirmaciones que Skinner hace a través de Walden Dos: "la economía es un juego de niños". Esta afirmación interpreta que la Economía y la ciencia política carecen de un sustento empírico verificable que permita una correlación lógica entre sus teorías y sus aplicaciones reales. En ninguna de las dos existen experimentos concebidos, examinados, alterados, repetidos, etc.

Según Cuevas (1986), uno de los economistas colombianos más reconocidos, las ciencias sociales en general, a diferencia de las naturales, no son experimentales. Es decir, no pueden crear artificialmente condiciones ideales y controlables por el investigador para el estudio de los fenómenos. Esto significa que la experimentación, en el sentido que dan a este término las ciencias naturales, no es un método de investigación accesible a la ciencia económica. No está dentro de las posibilidades de un economista lograr que la sociedad deje de producir un año para indagar sobre los efectos de tal fenómeno.

Desde esta línea de pensamiento, Cuevas (1986) argumenta que existen fuerzas sociales reales que impiden tal experimentación; precisamente por esta razón la ciencia económica ha desarrollado sus propios métodos de investigación (no experimentales en el sentido de las ciencias naturales) que no sólo le han permitido ser consistente con tal circunstancia y con la explicación obj etiva que le corresponde del mundo real, sino que, quizás, hacen redundante la experimentación misma para muchos de los problemas que explica o pretende explicar.

Es un hecho que el conocimiento factual es el que, en última instancia, determina la validez 0 invalidez científica de un modelo lógica o internamente consistente. Sin embargo, para obtener esta información factual, en ausencia de condiciones experimentales, la ciencia económica debe recurrir a la historia y a la estadística (sus únicos instrumentos de observación directa de la realidad primaria), debe acudir a registros de hechos reales básicos sobre los cuales se 
fundamenta todo método científico (Cuevas, 1986).

En este punto cabe preguntarse si esta información "factual", procedente de la estadística y la historia, realmente permite otorgarle el grado de validez científica al modelo económico. Barlow y Hersen (1984) han demostrado que la estadística es una herramienta que, a pesar de sus muchas veces altos niveles de complejización matemática, no logra ofrecer el resultado para el cual fue creada: una fiabilidad en los resultados. Cuando se trata con disciplinas que se basan de una u otra forma en la conducta de los individuos bajo distintas perspectivas, es difícil que se llegue a estudios verídicos sobre un tema específico, como lo concluye también Catania (1974), puesto que los muestreos grupales aleatorios conllevan a una ambigüedad en los resultados.

La historia tampoco significa un pilar estable sobre el cual pueda efectivamente fundamentarse la validez de los modelos económicos. Como lo dice Skinner a través de sus interlocutores imaginarios en Walden Dos: "La historia no nos dice nada" (Skinner, 1948, p. 298). Y es válido su argumento, pues los hechos históricos no sucedieron en un ambiente controlado de donde se puedan extrapolar conclusiones verídicas sobre un caso determinado a estudiar, por lo cual hallar fundamentos en conclusiones que carecen de validez le resta credibilidad al trabajo deductivo procedente de dichos análisis.

En suma, es posible ver que mientras la economía olvide que el estudio de las relaciones sociales de producción se trastoca constantemente con la conducta de cada individuo como sujeto social en una determinada circunstancia, la relacionada con los fines de producción y utilización de recursos escasos difícilmente podrá llegar a unos cimientos sólidos sobre los cuales pueda efectivamente sostenerse una teoría dada. Mientras los economistas sigan teorizan- do sobre la idealización de la realidad, jamás podrán llegar a una conclusión válida, pues si bien es cierto que el alto nivel de matematización que tiene la disciplina crea un espejismo de dificultad que frecuentemente se asocia con credibilidad y validez, también es cierto que hipotéticamente es posible la matematización de cualquier fenómeno sin que éste efectivamente pueda catalogarse como científico.

\section{Referencias}

Barlow D. \& Hersen M (1984). Diseños experimentales de caso único. Barcelona: Martínez Roca.

Catania, A.C (1974). Investigación contemporánea en conducta operante. México: Editorial Trillas.

Cuevas, H. (1986). Introducción a la economía. Bogotá: Universidad Externado de Colombia.

Friedman, M. (1966). Capitalismo y libertad (1962). Madrid: Ediciones Rialp.

Marx, C. (1982). El capital: crítica de la economía política. México: Fondo de Cultura Económica. 3t.

Nicholson W. (2002). Microeconomic theory. London: Thompson Learning.

Ridley, Matt (1998). The origins of virtue: human instincts and the evolution of cooperation. New York: Penguin.

Skinner, B.F (1948). Walden Dos. Bogotá: Planeta.

Smith, A. (1776) Investigación acerca de la naturaleza y causas de la riqueza de las naciones. 